\title{
Pengaruh Estetika pada Minat Konsumen Terhadap Pembelian Smartphone Xiaomi di Jakarta Barat
}

\author{
Deynis Devlin dan Carunia Mulya Firdausy \\ Program Studi Manajemen Fakultas Ekonomi \& Bisnis \\ Universitas Tarumanagara \\ Email: deynisdevlin98@gmail.com
}

\begin{abstract}
This study aims to determine the effect of aesthetics on purchase intention mediated by functional value, social value, and emotional value. The population of this study was consumers who use Xiaomi smartphones. The sampling technique was by using non-probability sampling method. The method of analysis was by using PLS-SEM. The results showed that aesthetics had a positive and significant effect on consumer purchase intentions mediated by functional value, and aesthetics had a positive effect on consumer purchase intentions through emotional value mediation in West Jakarta.
\end{abstract}

Keywords: Aesthetic, functional value, social value, emotional value, purchase intention

Abstrak: Penelitian ini bertujuan untuk mengetahui pengaruh estetika terhadap minat pembelian yang dimediasi oleh nilai fungsional, nilai sosial, dan nilai emosional. Populasi penelitian ini adalah konsumen yang menggunakan smartphone Xiaomi. Teknik pengambilan sampel menggunakan metode non-probability sampling. Metode analisis menggunakan PLS-SEM. Hasil penelitian menunjukkan bahwa estetika memiliki pengaruh positif dan signifikan terhadap niat pembelian konsumen yang dimediasi oleh nilai fungsional, dan estetika memiliki efek positif pada niat pembelian konsumen melalui mediasi nilai emosional di Jakarta Barat.

Kata Kunci: estetika, nilai fungsional, nilai sosial, nilai emosional, minat pembelian

\section{LATAR BELAKANG}

Era teknologi memiliki perkembangan yang cepat mengikuti perkembangan kebutuh konsumen. Penggunaan teknologi komunikasi sudah berkembang dan memunculkan produk smartphone yang menjadi salah satu benda wajib bagi konsumen. Peningkatan jumlah pengguna smartphone berkembang setiap tahunnya, serta minat pembelian konsumen memiliki beberapa faktor sebagai penentu apakah konsumen akan membeli smartphone tersebut atau tidak. Kebutuhan akan smartphone mengalami peningkatkan berdasarkan pola konsumsi konsumen yang selalu menginginkan kemudahan dalam komunikasi yang dapat mendukung kegiatan mereka sehari-hari. Keputusan konsumen untuk membeli menjadi suatu hal penting untuk diperhatikan, karena hal ini akan menjadi pertimbangan bagaimana strategi pemasaran yang akan dilakukan oleh perusahaan kedepannya dalam mengahadapi berbagai macam bentuk persaingan.

Telepon pintar (smartphone) adalah telepon selular dengan mikroprosesor, memori, layar dan modem bawaan serta merupakan ponsel multimedia yang menggabungkan fungsionalitas Personal Computer sehingga menghasilkan telepon yang mewah, di mana terdapat pesan teks, kamera, pemutar musik, pemutar video, game, penggunaan email, tv digital, search engine, pengelola informasi pribadi, fitur GPS, jasa telepon internet dan bahkan terdapat telepon yang juga berfungsi sebagai kartu kredit (Williams \& Sawyer, 2011). 
Produk yang memuaskan akan menciptakan kesan positif konsumen terhadap produk yang digunakan, konsumen memperhatikan utilitas produk berdasarkan pengeluaran yang harus dikorbankan. Salah satu perusahaan yang mengembangkan teknologi komunikasi menjadi bisnis adalah perusahaan Xiaomi. Xiaomi merilis smartphone pertamanya pada bulan Agustus 2011. Di awal kemunculan smartphone Xiaomi, terdapat beberapa pesaing yang sudah memiliki nilai merek yang sangat kuat seperti Iphone, Samsung Galaxy, Oppo, Asus dan lain-lain. Merek Xiaomi masih menjadi pemula dibidang komunikasi ini, sehingga fitur-fitur yang ditawarkan masih terbilang belum dapat menyaingi pesaing lainnya. Selain itu harga produk smartphone Xiaomi ditentukan berdasarkan fitur dan spesifikasi yang berbedabeda.

Ketertarikan konsumen terhadap smartphone memiliki kemungkinan dirasakan melalui nilai estetika produk tersebut, melalui warna, penampilan, bentuk, keindahan, dan sentuhan. Pada dasarnya sebuah smartphone memiliki nilai estetika berdasarkan merek yang dinaunginya. Produk Xiaomi memanfaatkan estetika melalui desain modern, dan mengikuti perkembangan jaman. Minat pembelian konsumen bisa didasari melalui estetika produk yang ditawarkan.

Smartphone memiliki perbedaan kualitas dan manfaat berdasarkan tipe yang ditawarkan, kualitas fungsional, ketertarikan sosial dan pengaruh emosional akan mempengaruhi minat konsumen untuk dapat menimbulkan keinginan membeli produk. Fungsi produk dapat menimbulkan keinginan konsumen untuk melakukan pembelian berdasarkan manfaat yang dan kebutuhan konsumen.

Nilai sosial yang mendorong kedudukan konsumen, menimbulkan rasa untuk membeli sebagai produk yang memberikan pengaruh positif terhadap konsumen. Smartphone yang digunakan mampu memberikan kesan baik terhadap diri sendiri dan orang lain. Faktor nilai emosional mampu menjadi pendorong bagi konsumen untuk membeli produk, hal tersebut dikarenakan produk yang diketahui konsumen memberikan alasan agar memunculkan rasa senang dan kepuasan.

\section{KAJIAN TEORI}

Teori yang digunakan dalam penelitian ini adalah Theory of consumption value (Sheth et $a l .$, 1991). Teori ini menjelaskan bahwa pilihan konsumen merupakan fungsi dari bermacammacam nilai konsumsi, memberikan kontribusi yang berbeda dalam situasi pilihan apa pun, dan bersifat independen. Sheth el al. (1991) melakukan penelitian yang menunjukan emotional value sangat berpengaruh terhadap pengguna dan bukan pengguna, functional value menandakan pemilih berdasarkan fungsi, dan social value berpengaruh dalam menentukan merek yang akan dibelanjakan. Keinginan untuk melakukan pembelian barang dapat timbul berdasarkan adanya manfaat fungsional, utilitarian dan bagian fisik yang menonjol. Functional value diukur melalui atribut pilihan terhadap minat beli konsumen dimana terjadi hubungan yang saling mempengaruhi. Social value dapat mempengaruhi keinginan konsumen melalui adanya hubungan antara demografis, sosio-ekonomi, dan budaya-etnis. Emotional value diukur berdasarkan profil konsumen terhadap barang berdasarkan tampak dan keaslian produk, sehingga memunculkan respon emosional.

Aesthetic. Workman dan Caldwell (2007) menyatakan produk yang memiliki peran dasar berdasarkan ide-ide atau keunggulan tentang karakter produk. Sedangkan Bloch et al. (2003) mengatakan desain produk yang luar biasa membantu membedakan produk dari produk para pesaing dan memungkinkan untuk membuat perbedaan di pasar. Menurut Wang et al. (2013) mendefinisikan terjadinya pendekatan holistik dengan dua dimensi yaitu formalitas estetika 
yang dianggap praktis dan bermanfaat serta dimensi lain yang menangkap daya tarik emosional.

Functional value. Sweeney dan Soutar (2001) menyatakan bahwa nilai fungsional merupakan keinginan konsumen yang bersumber dari persepsi kualitas dan didasari kinerja produk yang diharapkan konsumen, dimana minat konsumen terhadap produk terdapat pengaruh dari pengurangan biaya yang berarti jangka pendek dan pemanfaatan produk yang merupakan jangka panjang. Pernyataan Sanchez et al. (2006) menyatakan nilai rasional dan ekonomi dari individu mengenai kualitas bentuk, produk, dan layanan.

Social value. Menurut Sheth et al. (1991) mendefinisikan bahwa nilai sosial adalah kemauan konsumen yang dirasakan dan diperoleh dari hubungan sosial dengan satu atau lebih kelompok sosial tertentu. Rintamaki et al. (2006) mengatakan bahwa interaksi atau hubungan dengan orang lain yang dapat memuaskan pemenuhan keperluan diri sendiri dengan memanfaatkan nilai produk. Sweeney dan Soutar (2001) mendefinisikan nilai sosial adalah tingkat nilai suatu produk untuk meningkatkan diri didandangan sosial.

Emotional value. Sheth et al. (1991) menyatakan nilai emosioanal merupakan manfaat yang dirasakan dan diperoleh dari hubungan sosial untuk membangkitkan perasaan atau keadaan afektif dan produk dikaitkan dengan perasaan tertentu serta diukur pada tingkatan perasaan terhadap konsumen yang menggunakan produk. Sedangkan Sweeney dan Soutar (2001) menjelaskan kegunaan produk yang dapat menimbulkan pengaruh perasaan atau emosional terhadap konsumen.

Purchase intention. Berdasarkan Lu et al. (2014) mendefinisikan bahwa minat pembelian merupakan kesediaan konsumen untuk membeli produk yang tersedia pada waktu tertentu dalam situasi tertentu. Menurut Belch dan Belch (2015) minat pembelian adalah pencocokan motif pembelian dengan atribut atau karakteristik pertimbangan pengguna merek. Selanjutnya Kotler dan Keller (2012) menyatakan bahwa menggerakan konsumen agar memutuskan untuk membeli suatu merek atau melakukan tindakan terkait dengan pembelian.

Berdasarkan penjelasan variabel diatas yaitu aesthetic, functional value, social value, emotional value, dan purchase intention dapat dilihat dari hipotesis berikut.

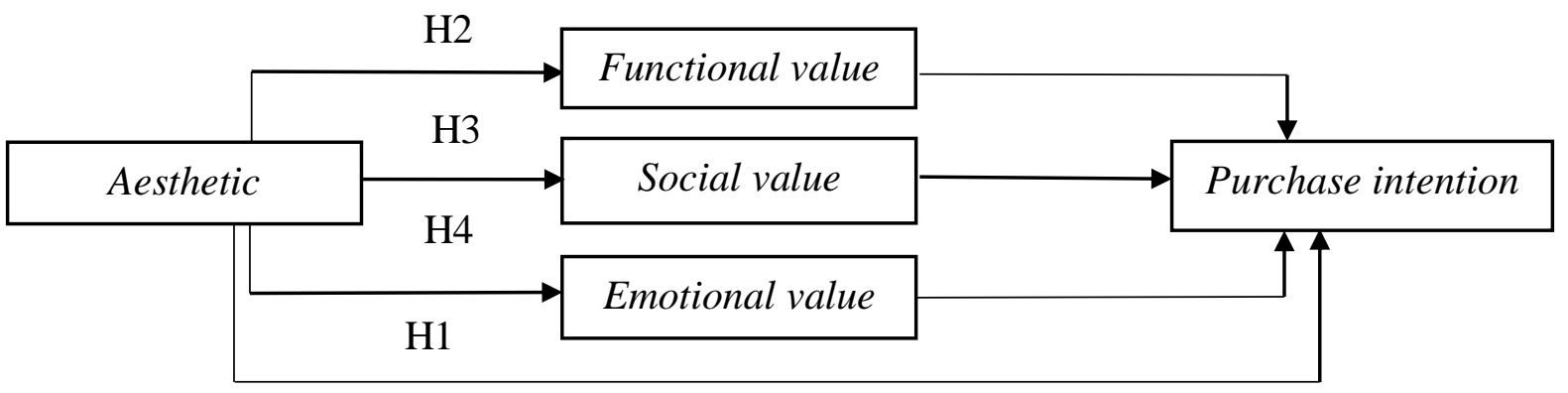

Gambar 1. Kerangka Pemikiran

Hipotesis dari model yang dibangun di atas adalah sebagai berikut:

$\mathrm{H}_{1}$ : Terdapat pengaruh positif dan signifikan hubungan antara aesthetic terhadap purchase intention produk smartphone Xiaomi 
$\mathrm{H}_{2}$ : Terdapat pengaruh positif dan signifikan hubungan antara aesthetic terhadap purchase intention melalui mediasi functional value produk smartphone Xiaomi

$\mathrm{H}_{3}$ : Terdapat pengaruh positif dan signifikan hubungan antara aesthetic terhadap purchase intention melalui mediasi social value produk smartphone Xiaomi

$\mathrm{H}_{4}$ : Terdapat pengaruh positif dan signifikan hubungan antara aesthetic terhadap purchase intention melalui mediasi emotional value produk smartphone Xiaomi

\section{METODOLOGI}

Desain yang digunakan dalam penelitian ini adalah penelitian deskriptif, yakni menggunakan analisis kuantitatif untuk mendeskripsikan penelitian dalam studi ini. Populasi yang digunakan adalah mahasiswa dan masyarakat yang berdomisili di Cengkareng, Jakarta Barat. Teknik pengambilan sampel menggunakan metode non-probability sampling yang memanfaatkan teknik purposive sampling. Jumlah sampel yang akan digunakan sebanyak 30 sampai 500 agar mencapai hasil data yang baik (Sugiyono, 2015).

Cara pengambilan hasil responden dilakukan dengan cara penyebaran kuesioner melalui bantuan google form kepada pada pengguna smartphone serta konsumen yang mengetahui produk ini. Penyebaran dilakukan melalui orang terdekat yang menggunakan smartphone Xiaomi terlebih dahulu lalu disebarkan melalui media sosial dengan memanfaatkan aplikasi komunikasi. Penyebaran juga dilakukan terhadap beberapa grup obrolan yang terdapat di media sosial.

Instrumen pengumpulan data dari responden menggunakan pengukuran skala likert. Skala dibagi menjadi 5 bagian yaitu 1 adalah sangat tidak setuju, 2 adalah tidak setuju, 3 adalah netral, 4 adalah setuju, 5 adalah sangat setuju. Setiap variabel memilki indikator yang ditujukan kepada responden, variabel aesthetic terdiri dari lima belas indikator, functional value terdiri dari tiga indikator, social value terdiri dari enam indikator, emotional value terdiri dari enam indikator, dan purchase intention terdiri dari empat indikator.

\section{HASIL ANALISIS DATA}

Deskripsi responden penelitian ini sebagai berikut. Pertama, jenis kelamin, responden penelitian ini didominasi oleh jenis kelamin wanita sebanyak 53 persen dan sisanya pria sebanyak 47 persen. Kedua, berdasarkan usia, responden umumnya berada dalam rentan usia 17-25 tahun sebanyak 79 persen, posisi kedua rentan usia 26-35 sebanyak 17 persen, dan posisi ketiga berusia lebih dari 35 tahun sebanyak 4 persen. Ketiga, status pekerjaan, bagian pelajar/mahasiswa mendominasi dengan jumlah 80 persen dan keempat berdasarkan pendidikan terakhir didominasi oleh tingkatan SMA dengan jumlah sebanyak 73 persen.

\section{Analisis Validitas, Reliabilitas dan Hipotesis}

Nilai yang tertera pada Averange Variance Extracted (AVE) dari setiap variabel memiliki nilai lebih besar dari 0,5 sehingga dapat disimpulkan bahwa seluruh variabel telah memenuhi syarat untuk dilakukan pengujian (Tabel 1).

Tabel 1. Hasil Validitas Average Variance Extracted (AVE)

\begin{tabular}{|c|c|}
\hline Variabel & Average Variance Extracted (AVE) \\
\hline Aesthetic & 0.568 \\
\hline Aesthetic-Beauty & 0.539 \\
\hline Aesthetic - Color & 0.515 \\
\hline Aesthetic - Design & 0.573 \\
\hline
\end{tabular}


Deynis dan Carunia: Pengaruh Dimensi Orientasi Kewirausahaan dan...

\begin{tabular}{|c|c|}
\hline Aesthetic - Touch & 0.610 \\
\hline Emotional value & 0.542 \\
\hline Functional value & 0.546 \\
\hline Purchase intention & 0.789 \\
\hline Social value & 0.542 \\
\hline
\end{tabular}

Sumber: diolah dari data penelitian, 2020

Hasil Cross Loadings pada semua nilai disetiap indikator pada variabel telah melebihi syarat dengan minimal lebih dari $0,4(>0,4)$ dan jika nilai lebih dari $0,7(>0,7)$ dapat disebut nilai indikator memiliki nilai yang baik (Henseler et al., 2009) (Tabel 2).

Tabel 2. Hasil Validitas Cross Loadings

\begin{tabular}{|c|c|c|c|c|c|c|c|c|c|}
\hline & A & B & $\mathrm{C}$ & D & $\mathbf{T}$ & EV & FV & $\mathbf{P I}$ & SV \\
\hline $\mathrm{AB} 1$ & .463 & 671 & .274 & .167 & .330 & 0.242 & .218 & .22 & 0.341 \\
\hline $\mathrm{AB} 2$ & 473 & 646 & 190 & .305 & .322 & .295 & 258 & .308 & 0.125 \\
\hline AB3 & 587 & 4 & 243 & 393 & 397 & 356 & 279 & .195 & 0.296 \\
\hline $\mathrm{AB} 4$ & 0.613 & 0.810 & 9 & 0.344 & 0411 & 404 & 0387 & 5 & 0388 \\
\hline $\mathrm{AC}$ & 0.298 & 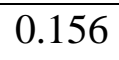 & 0.505 & 0.181 & 0085 & 9 & 0 & 0.247 & .167 \\
\hline $\mathrm{AC} 2$ & 472 & 0.307 & 0.761 & 0.112 & 0.272 & 0.328 & 0.278 & 0.234 & 0.269 \\
\hline $\mathrm{AC} 3$ & 0.465 & 0.138 & 0.744 & 0.231 & 0.283 & 0.260 & 0.255 & 0.310 & 0.379 \\
\hline $\mathrm{AC} 4$ & 522 & .289 & 833 & 0.183 & 0.287 & 0.300 & .272 & 0.328 & 0.475 \\
\hline AC5 & 68 & 2 & 4 & 29 & 0 & .391 & 35 & .330 & 0.591 \\
\hline AD1 & 0.346 & 3 & 50 & 0.563 & w & 167 & 171 & - & .048 \\
\hline AD2 & 659 & 382 & 76 & 828 & 493 & 436 & .402 & 0.336 & .437 \\
\hline AD3 & 0.659 & 0.354 & 0.266 & 0.851 & 0.461 & 0.448 & 0.405 & 0.345 & 0.436 \\
\hline AD4 & 0.609 & 0.291 & 0.229 & 0.752 & 0.522 & 0.429 & 0.392 & 0.389 & 0.392 \\
\hline AT1 & 587 & .303 & .364 & 0.313 & 7 & 0.377 & 0.200 & 0.286 & 0.394 \\
\hline AT2 & 00 & 0.437 & 11 & 3 & 0021 & 2 & 0.334 & 0.329 & 360 \\
\hline AT3 & 13 & 349 & 16 & 457 & 761 & 369 & 434 & .284 & 0.423 \\
\hline AT4 & 704 & 0.458 & .275 & 0.533 & 0.795 & 0.468 & 0.465 & 0.522 & 0.480 \\
\hline EV1 & 483 & .430 & 0.287 & 0.392 & 0.359 & 0.736 & 0.495 & 0.513 & 0.461 \\
\hline EV2 & 09 & 0 & 51 & 19 & 416 & 8 & 80 & 6 & 0.426 \\
\hline EV3 & 0.701 & 0.204 & 0.200 & 0.721 & ש. & 0.707 & 0.400 & 0.400 & 0.588 \\
\hline EV4 & 0 & ) & 9 & 0.400 & 0.443 & 0 & 0.500 & 0.448 & 0 \\
\hline EV5 & 269 & 0.156 & 0.164 & 0.279 & 0.203 & 649 & 0.161 & 0.429 & 0.367 \\
\hline EV6 & 480 & 0.278 & 0.435 & 0.331 & 0.386 & 0.679 & 0.443 & 0.607 & 0.578 \\
\hline FV1 & 512 & 0.328 & .388 & 0.416 & 0.401 & 0.463 & 0.825 & 0.509 & 0.444 \\
\hline FV2 & 87 & 0.257 & 6 & 7 & 0.362 & 0 & 7 & 0.519 & 0.491 \\
\hline FV3 & 0.351 & 0.293 & 0.205 & 0.315 & 0.248 & 0.352 & 0.655 & 0.382 & 0.354 \\
\hline PI1 & 0.460 & 0.254 & 0.372 & 0.361 & 0.379 & 0.590 & 0.516 & 0.845 & 0.556 \\
\hline PI2 & 0.557 & 0.357 & 0.451 & 0.406 & 0.451 & 0.637 & 0.554 & 0.926 & 0.593 \\
\hline $\mathrm{PI} 3$ & 50 & 8 & 0 & 0.367 & 2 & 4 & 0.615 & 0.925 & 0.5 \\
\hline
\end{tabular}


Deynis dan Carunia: Pengaruh Dimensi Orientasi Kewirausahaan dan...

\begin{tabular}{|l|l|l|l|l|l|l|l|l|l|}
\hline PI4 & 0.460 & 0.303 & 0.309 & 0.329 & 0.428 & 0.572 & 0.592 & $\mathbf{0 . 8 5 5}$ & 0.492 \\
\hline SV1 & 0.565 & 0.372 & 0.464 & 0.387 & 0.465 & 0.485 & 0.393 & 0.436 & $\mathbf{0 . 7 2 4}$ \\
\hline SV2 & 0.527 & 0.348 & 0.432 & 0.360 & 0.431 & 0.474 & 0.512 & 0.474 & $\mathbf{0 . 7 8 5}$ \\
\hline SV3 & 0.432 & 0.232 & 0.352 & 0.363 & 0.336 & 0.398 & 0.321 & 0.418 & $\mathbf{0 . 6 9 9}$ \\
\hline SV4 & 0.427 & 0.244 & 0.411 & 0.256 & 0.353 & 0.526 & 0.412 & 0.449 & $\mathbf{0 . 7 2 7}$ \\
\hline SV5 & 0.530 & 0.242 & 0.414 & 0.463 & 0.448 & 0.592 & 0.593 & 0.502 & $\mathbf{0 . 7 9 5}$ \\
\hline SV6 & 0.393 & 0.316 & 0.364 & 0.225 & 0.278 & 0.448 & 0.309 & 0.409 & $\mathbf{0 . 6 8 0}$ \\
\hline
\end{tabular}

Sumber: diolah dari data penelitian, 2020

Hasil multikolinearitas yang diukur menggunakan VIF inner model, dapat disimpulkan bahwa pada setiap variabel tidak terdapat multikoliniearitas dikarenakan nilai VIF kurang dari $5(>5)$ (Tabel 3).

Tabel 3. Hasil Reliabilitas Multikolinearitas

\begin{tabular}{|c|c|c|}
\hline \multicolumn{1}{|c|}{ Variabel } & Nilai & Keterangan \\
\hline $\mathrm{PI}=\mathrm{f}(\mathrm{A}, \mathrm{FV}, \mathrm{SV}, \mathrm{EV})$ & & \\
Aesthetic & $\mathrm{VIF}=2.084$ & Tidak ada Mulltikolinearitas \\
Functional value & $\mathrm{VIF}=1.797$ & Tidak ada Mulltikolinearitas \\
Social value & $\mathrm{VIF}=2.260$ & Tidak ada Mulltikolinearitas \\
Emotional value & $\mathrm{VIF}=2.175$ & Tidak ada Mulltikolinearitas \\
\hline
\end{tabular}

Sumber: diolah dari data penelitian, 2020

\section{DISKUSI}

Berdasarkan hasil hipotesis, menunjukan bahwa hipotesis pertama $\left(\mathrm{H}_{1}\right)$ memiliki nilai signifikansi untuk variabel aesthetic berpengaruh terhadap purchase intention sebesar 0,813 yang berarti nilai ini melebihi batas 0,05 sehingga menyatakan hipotesis pertama tidak didukung. Kemudian hasil hipotesis kedua menunjukan pengaruh signifikan sebesar 0,003 untuk variabel aesthetic dimediasi functional value berpengaruh terhadap purchase intention yang berarti nilai signifikansi dibawah 0,05 sehingga dinyatakan didukung dan memiliki pengaruh positif yang signifikan. Selanjutnya hipotesis ketiga menunjukan nilai signifikansi sebesar 0,152 yang seharusnya memiliki nilai batas dibawah 0,05 sehingga pengaruh aesthetic terhadap purchase intention yang dimediasi social value tidak didukung. Terakhir hasil uji hipotesis keempat memiliki nilai signifikansi sebesar 0,001 sehingga telah memenuhi syarat kurang dari 0,05 . Hasil tersebut menyatakan pengaruh aesthetic terhadap purchase intention dengan dimediasi emotional value didukung dan memiliki pengaruh positif yang signifikan. (Tabel 4)

Tabel 4. Hasil Hipotesis

\begin{tabular}{|l|c|c|c|}
\hline \multicolumn{1}{|c|}{ Variabel } & $\boldsymbol{\beta}$ & $\boldsymbol{p}$-value & Keterangan \\
\hline $\mathrm{H}_{1}:$ Aesthetic $\rightarrow$ Purchase intention & 0.021 & 0.813 & Tidak didukung \\
\hline $\begin{array}{l}\mathrm{H}_{2}: \text { Aesthetic } \rightarrow \text { Functional value } \rightarrow \\
\text { Purchase intention }\end{array}$ & 0.308 & 0.003 & Didukung \\
\hline $\begin{array}{l}\mathrm{H}_{3}: \text { Aesthetic } \rightarrow \text { Social value } \rightarrow \text { Purchase } \\
\text { intention }\end{array}$ & 0.163 & 0.152 & Tidak didukung \\
\hline $\begin{array}{l}\mathrm{H}_{4}: \text { Aesthetic } \rightarrow \text { Emotionsl Value } \rightarrow \\
\text { Purchase intention }\end{array}$ & 0.381 & 0.001 & Didukung \\
\hline
\end{tabular}

Sumber: diolah dari data penelitian, 2020 


\section{PENUTUP}

Hasil pengujian hipotesis studi ini menunjukan bahwa minat pembelian produk smartphone Xiaomi oleh mahasiswa dan masyarakat yang berdomisili di Cengkareng tidak memiliki pengaruh menurut aesthetic produk. Hal yang sama juga terkait dengan kualitas diri dan persepsi hidup serta ekspresi diri yang juga tidak berpengaruh secara signifikan terhadap minat pembelian.

Hasil ini berbanding terbalik dengan functional value dan emotional value. Hasil functional value menyatakan bahwa masyarakat dan mahasiswa memiliki minat pembelian berdasarkan keunggulan dalam kemampuan kinerja, kemudahan dalam menggunakan smartphone Xiaomi, ketahanan produk dalam penggunaan dan umur baterai. Faktor ini menimbulkan keinginan untuk melakukan pembelian.

Terkait emotional value, variabel ini memiliki pengaruh dalam meningkatkan minat pembelian masyarakat dan mahasiswa terhadap produk smartphone Xiaomi. Hal tersebut terjadi karena adanya rasa santai dalam penggunaan produk, merasa senang ketika menggunakan smartphone Xiaomi yang sesuai dengan keinginan konsumen, menggunakan produk yang lebih unggul dari para pesaing, menjadi perhatian, dan merasakan senang dalam penggunaan produk smartphone Xiaomi.

Namun hasil penelitian ini memiliki keterbatasan terkait jumlah sampel dan penggunaan variabel. Oleh karna itu untuk meningkatkan kualitas penelitian ini disarankan menambah jumlah sampel responden dan menambah variabel-variabel lainnya selain dari variabel yang telah digunakan dipenelitian ini. Selain itu, untuk penelitian selanjutnya disarankan untuk melakukan penyebaran kuesioner secara langsung terhadap konsumen agar menerima respon yang lebih baik dan benar-benar dapat mewakili sampel yang dibutuhkan.

Untuk perusahaan Xiaomi sendiri disarankan agar terus meningkatkan kualitas produknya, misalnya, dengan pengaturan warna smartphone tidak memiliki warna yang berbeda dan pengembangan citra produk. Semua ini dimaksudkan untuk meningkatkan minat konsumen membeli smartphone Xiaomi.

\section{DAFTAR PUSTAKA}

Bloch, P.T., Brunel, F.F., \& Arnold, T.J., (2003). Individual differences in the centrality of visual product aesthetics: Concept and measurement, Journal of Consumer Research, 29. 551-565.

Henseler, J., Ringle, C.M., \& Sinkovics, R.R. (2009). The use of partial least squares path modeling in international marketing. Advances in International Marketing, 20 (1), 277-319.

Kotler, P., \& Keller, K. L. (2012). Marketing Management. England: Pearson Education Limited.

Lu, L., Chang, W., \& Chang, H. (2014). Consumer attitudes toward blogger's sponsored recommendations and purchase intention: The effect of sponsorship type, product type, and brand awareness. Computers in Human Behavior, 34, 258-266.

Rintamaki, T., Kanto, A., Kuusela, H. \& Spence, M.T. (2006), Decomposing the value of department store shopping into utilitarian, hedonic and social dimensions: evidence from Finland. International Journal of Retail \& Distribution Management, 34 (1), 624.

Sanchez, J., Callarisa, LL.J., Rodríguez, R.M., \& Moliner, M.A. (2006). Perceived value of the purchase of a tourism product. Tourism Management, 27 (4), 394-409.

Sheth, J. N., Newman, B. I., \& Gross, B. L. (1991). Why we buy what we buy: A theory of consumption values. Journal of business research, 22 (2), 159-170. 
Sugiyono. (2015). Metode Penelitian Kuantitatif, Kualitatif Dan Kombinasi (Mixed Methods). Bandung; ALFABETA.

Sweeney, J. C., \& Soutar, G. N. (2001). Consumer perceived value: The development of a multiple item scale. Journal of Retailing, 77 (2), 203-220.

Wang, Y., Cruthirds, K., Axinn, C. \& Guo, C. (2013), In search of aesthetics in consumer marketing: an examination of aesthetic stimuli from the philosophy of art and the psychology of art, Academy of Marketing Studies Journal, 17 (2), 37-55.

Williams, B.K. \& Sawyer, S.C. (2011). Using Information Technology: A Practical Introduction to Computers \& Communications. New York: McGraw-Hill.

Workman, J.E. \& Caldwell, L.F., (2007). Centrality of visual product aesthetics, tactile and uniqueness needs of fashion consumers. International Journal of Consumer Studies, $31,589-596$. 